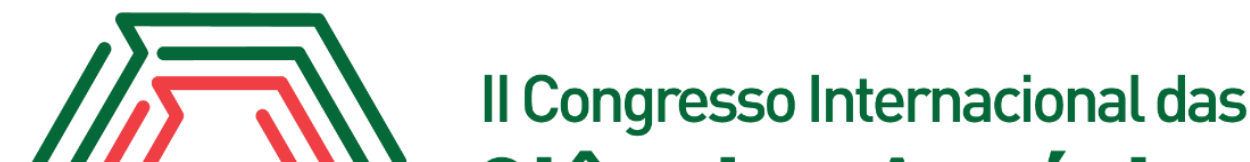 Ciências Agrárias COINTER - PDVAgro 2017
}

\section{FEIRA DE AGRICULTURA FAMILIAR E ECONOMIA SOLIDÁRIA DO VALE DO AÇU: A IMPORTANCIA E A VALORIZAÇÃO DA AGRICULTURA FAMILIAR E O HOMEM E A MULHER DO CAMPO}

\author{
Apresentação: Relato de Experiência \\ Valéria Valesca da Silva Brito ${ }^{1}$; Francisca das Chagas de Oliveira ${ }^{2}$; Paulina Alves da \\ Silva $^{3}$; Ana Paula Pereira dos Santos ${ }^{4}$; Monalisa Porto Araújo ${ }^{5}$
}

\section{Introdução}

A agricultura familiar é sempre lembrada pela sua importância, quando se trata em geração de empregos e pelo autoconsumo. Nos dias atuais busca-se por uma vida mais saudável, sem o uso de insumos químicos externos, e a agricultura familiar, em sua maioria busca não fazer o uso desses insumos, por isso a grande importância de enaltecer e valorizar a produção familiar, e foi nessa perspectiva que a IFAVESVA foi criada, para mostrar a importância e o que é produzido do Vale do Açu.

\section{Relato de Experiência}

Percebendo a grande importância da agricultura familiar do Vale do Açu, que professores do Instituto Federal de Educação, Ciência e Tecnologia do Rio Grande do Norte, com a ajuda de profissionais da agroecologia, alunos do instituto e agricultores, tiraram do papel a I Feira de Agricultura Familiar e Economia Solidária do vale do Açu. As feiras são os mais antigos lugares de comercialização existentes que ainda perduram no tempo. São encontrados desde os vilarejos e pequenos municípios, como nos grandes centros urbanos. Onde podemos encontrar a participação de pequenos agricultores familiares e feirantes/ comerciantes, estes últimos que adquirem produtos dos ceasas para comercializa-los em feira livre (BADUE et al., 2011).

Com caráter educativo e social por meio das relações sociais que aconteceram durante a Feira.

A I FAFESVA, foi uma oportunidade de expor o que é produzido no campo, e difundir valores

\footnotetext{
${ }^{1}$ Tecnologia em Agroecoloecologia, IFRN,valeria_vales_ca@hotmail.com
}

${ }^{2}$ Licenciatura em Química, IFRN, paulinaalvesdasilva@yahoo.com.br 
agroecológicos e de valorização do homem e da mulher do campo por meio de reflexões e rodas de conversas que aconteciam no momento da Feira, ou seja, existia uma relação social da venda dos produtos, mas também acontecia uma relação de status político, econômico, social e epistemológico. Toda articulação da I FAFESVA, se deu por meio de reuniões com os envolvidos, ou seja, com alunos e produtores interessados em expor seus produtos.

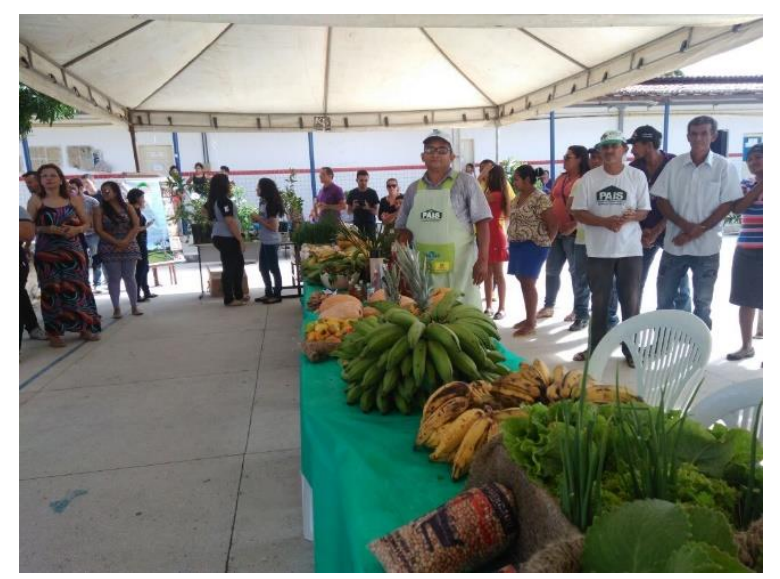

Imagem 1: Banca de hortaliças e frutas. Fonte: Própria

\section{Considerações}

A I FAFESVA, foi uma grande oportunidade não só para os alunos do IFRN vivenciarem de perto os aspectos e os produtos do homem do campo, como também foi de grande valia para os produtores do vale, pois neste momento houve troca de saberes, e na oportunidade foi criada uma rede de contatos, para que haja futuras parcerias, como aulas de campo e a divulgação dos produtos que foram expostos na feira.

Também, deixou janelas para oportunidades de produção de uma nova feira, com os primeiros e possivelmente com novos produtores, enriquecendo e mostrando a economia do vale para todo o estado.

\section{Referências}

BADUE, Ana Flávia Borges et al. Caminhos para Práticas de Consumo Responsável: Parceria entre Consumidores e Produtores na Organização de Feiras. São Paulo: Instituto Kairós, 2011. 44 f. 